\title{
Study of endometrial and cervical histopathology in adenomyosis
}

\author{
Anandakumari Matangi*, Alpha Manukonda, Abhizna Bommiti
}

\begin{abstract}
Department of Obstetrics and Gynecology, Government Victoria Hospital, Andhra Medical College, Visakhapatnam,
\end{abstract} Andhra Pradesh, India

Received: 03 March 2020

Accepted: 16 March 2020

\section{*Correspondence:}

Dr. Anandakumari Matangi,

E-mail: drak1973@gmail.com

Copyright: (C) the author(s), publisher and licensee Medip Academy. This is an open-access article distributed under the terms of the Creative Commons Attribution Non-Commercial License, which permits unrestricted non-commercial use, distribution, and reproduction in any medium, provided the original work is properly cited.

\begin{abstract}
Background: Hysterectomy is the most common gynaecological surgery performed in the perimenopausal and postmenopausal women all over the world. One of the most common cause of AUB is Adenomyosis based on histopathological evidence and the ultimate mainstay stay of treatment is hysterectomy in those patients not responding to medical therapy. Endocervical and Endometrial histopathology in adenomyosis are studied in this study. Objective of this study was to analyses various histopathological changes of endometrium and cervix in hysterectomy specimens showing features of adenomyosis.

Methods: This is a retrospective study conducted at Government Victoria Hospital for Women and Children, Visakhapatnam, Andhra Medical College for a period of one year from January 2019 to December 2019.100 cases with histopathology reports of hysterectomy specimens showing changes suggestive of adenomyosis were studied for 1 year. Those cases which showed features of adenomyosis were taken and the preoperative details and procedures done on the patient were retrieved and endometrial and cervical biopsy, Pap Smear changes of these patients were studied.

Results: Out of 100 cases, 37 members (majority) showed features of atrophic endometrium, 69 members (majority) showed features of chronic cervicitis, about 58 members (majority) showed inflammatory changes in Pap Smear. In the 100 cases, 75 cases are in perimenopausal age group i.e., 40-50 years, 80 of them are multiparous women, 85 members had mild to moderate degree of anaemia while only about 15 members had severe anemia. Adenomyosis was found to be the leading cause of AUB.

Conclusions: Adenomyosis is one the leading causes of AUB and hence also an important cause of hysterectomy in those with failed medical therapy. Histopathological changes of endometrium and cervix are analyzed from D and C and Pap Smear reports of patients whose specimens are confirmed to be having adenomyosis.
\end{abstract}

Keywords: Abnormal menstrual bleeding, Adenomyosis, Histopathology

\section{INTRODUCTION}

Adenomyosis is a benign uterine disorder in which endometrial glands and stroma are pathologically demonstrated in the uterine myometrium and it is considered a specific entity in the PALM-COEIN FIGO classification of causes of abnormal uterine bleeding. ${ }^{1}$

\section{Definition}

Adenomyosis is a common benign condition of uterus characterised by presence of ectopic endometrial glands within myometrial tissue. The presence of ectopic endometrial glands and stroma induces a hypertrophic and hyperplastic reaction in the surrounding myometrial tissue. 
Types

- Diffuse

- Focal

Symptoms $^{2,3}$

- Menorrhagia

- Dysmenorrhea

- Dyspareunia

- Pelvic pain

- Sub fertility

Signs

- Abdominal examination-uterus enlarged (not more than 14 weeks)

- Pelvic examination-uniform uterine enlargement with no restriction of mobility

- Uterus may be softer than normal

\section{Diagnostic criteria ${ }^{4}$}

- Grossly- pinpoint/small cystic areas of haemorrhage seen within the myometrium

- The microscopic criteria for the diagnosis of adenomyosis were the presence of endometrial glands and stroma in the myometrium more than one low power field away from the endomymetro junction

- Diagnosis of adenomyosis on clinical findings alone is usually difficult

- Imaging plays an important role in evaluation of myometrial lesions and the common diagnostic modalities available in op basis are transabdominal sonography (TAS) and transvaginal sonography (TVS).

\section{Criteria for adenomyosis in TVS}

- Asymmetrical myometrial thickening

- Heterogenous area within myometrium

- Hyperechoic region surrounded by hypoechoic area

- No discrete myometrial mass

- Contour of uterus unaltered

Objectives of this study was to analyse various histopathological changes of endometrium and cervix in hysterectomy specimens showing features of adenomyosis.

\section{METHODS}

This is a retrospective study conducted at Government Victoria Hospital for Women and Children, Visakhapatnam, Andhra Medical College for a period of one year from January 2019 to December 2019. 100 cases with histopathology reports of hysterectomy specimens showing changes suggestive of adenomyosis were studied. The specimens were processed routinely and stained with hematoxylin and eosin stain and examined microscopically. Those cases showed features of adenomyosis were taken and the preoperative details and procedures done on the patient were retrieved and endometrial and cervical biopsy, Pap Smear changes of these patients were studied.

\section{Inclusion criteria}

- Hysterectomy specimens with histopathological features suggestive of adenomyosis.

\section{Exclusion criteria}

- Hysterectomy done for complaints other than AUB and malignancy

- Specimen with histopathological features other than adenomyosis.

A record of the patients data was retrieved and patients age, parity, presenting complaint, signs, sonography findings, blood and other basic investigations like Pap Smear and clinical indication for hysterectomy were recorded.

Investigations done were complete blood counts, blood grouping and typing, screening tests for HIV, HbsAg, VDRL, random blood sugars, TSH, complete urine examination.

Those patients who were followed up and no response to medical therapy with no improvement in general condition of the patient or further detoriation and whose family is complete were posted for hysterectomy after checking for surgical fitness of the patient. Pap Smear along with $\mathrm{D}$ and $\mathrm{C}$ is done pre operatively and sent for HPE. Post hysterectomy specimen is also sent for histopathological examination and the histopathological reports were studied.

\section{RESULTS}

A total of 100 cases were included in the study. Age of the patients ranged from 35 to 65 years. The largest group was of perimenopausal age (40-50 years) contributing to about 75 members. In this age group, adenomyosis was the commonest pathology. Multiparous women in perimenopausal age (40-50 years) accounted for the highest number of cases presenting with symptoms of AUB. In this age group adenomyosis was found to be the most common cause of AUB, followed by leiomyoma. Endometrial pattern commonly seen was atrophic endometrium in about 37 cases, followed by proliferative phase and hyperplasia. Other patterns like endometrial adenocarcinoma, endometrial polyps were also encountered. Chronic non-specific cervicitis was the most common cervical pathology seen in around 69 cases and squamous cell carcinoma was also encountered. About 58 cases showed inflammatory changes in Pap Smear. Most 
of the women with adenomyosis were found to be anaemic with about 85 cases having mild to moderate degree of anaemia and only 15 cases had severe anemia.

- Age group

- Causes of AUB

- Parity

- Hb levels and degrees of anemia

- Histopathological changes of endometrium

- Histopathological changes of cervix

- Pap Smear.

\section{Age group}

Figure 1 shows that out of 100 cases, only 2 members were in 35-40 years age group, about 35 members are 4045 years old, 40 members were of 45-50 years old, 12 members were in age group 50-55 years, 8 members in 55-60 years and only 3 members were $>60$ years.

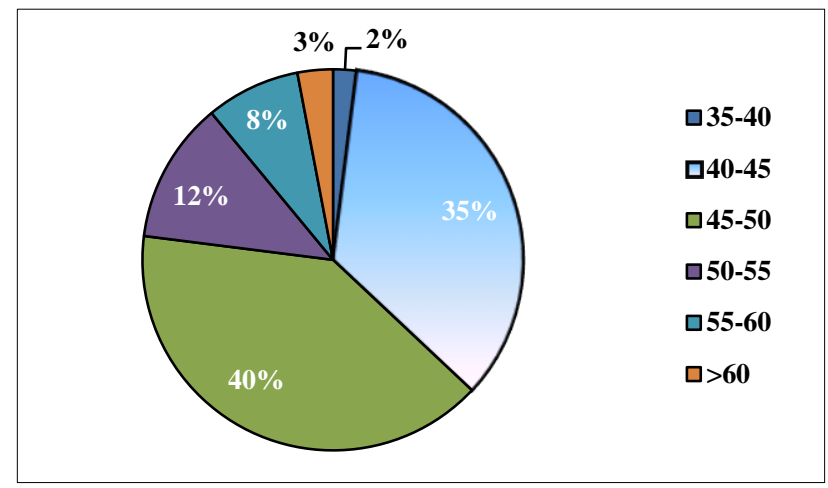

Figure 1: Age group.

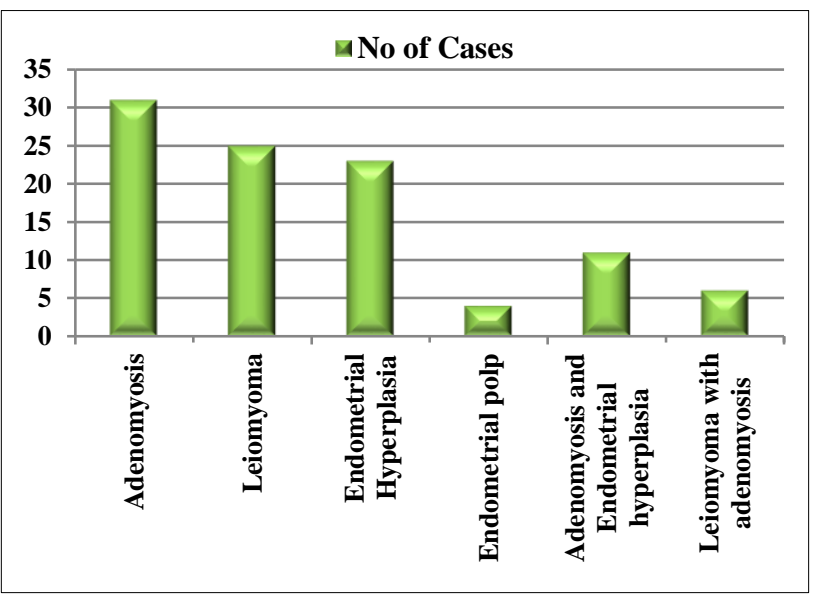

Figure 1: Causes of AUB.

\section{Causes of $A U B$}

Figure 2 shows that adenomyosis was the leading cause of menorrhagia or AUB i.e. about $31 \%$, followed by leiomyoma accounting to about $25 \%, 23 \%$ due to endometrial hyperplasia, $11 \%$ due to adenomyosis along with endometrial hyperplasia, about $6 \%$ having both adenomyosis with leiomyoma and about $4 \%$ having endometrial polyp.

\section{HB levels and degrees of anaemia}

Figure 3 shows degrees of anemia based on $\mathrm{Hb}$ levels i.e. about 9-11 g having mild anemia, 7-9 having moderate degree of anemia and $<7 \mathrm{~g}$ having severe degree of anemia. This is mainly due to blood loss as heavy menstrual bleeding during the cycles. However, anaemia due to adenomyosis is usually mild to moderate degree. 85 cases have mild to moderate degree of anaemia whereas only 15 cases had severe degree of anaemia.

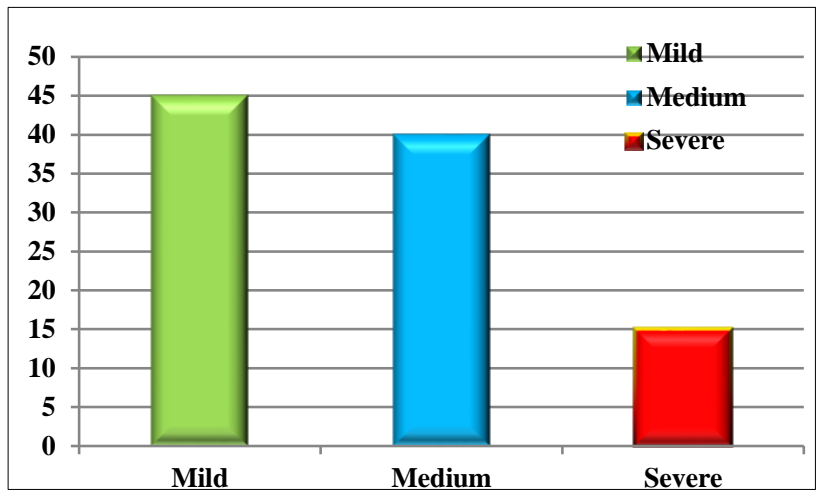

Figure 3: HB levels and degrees of anaemia.

\section{Parity}

Figure 4 shows of parity of the women.83 cases were multiparous (P3-P5), only 6 cases were nulliparous and 4 cases were grand multipara (> P7).

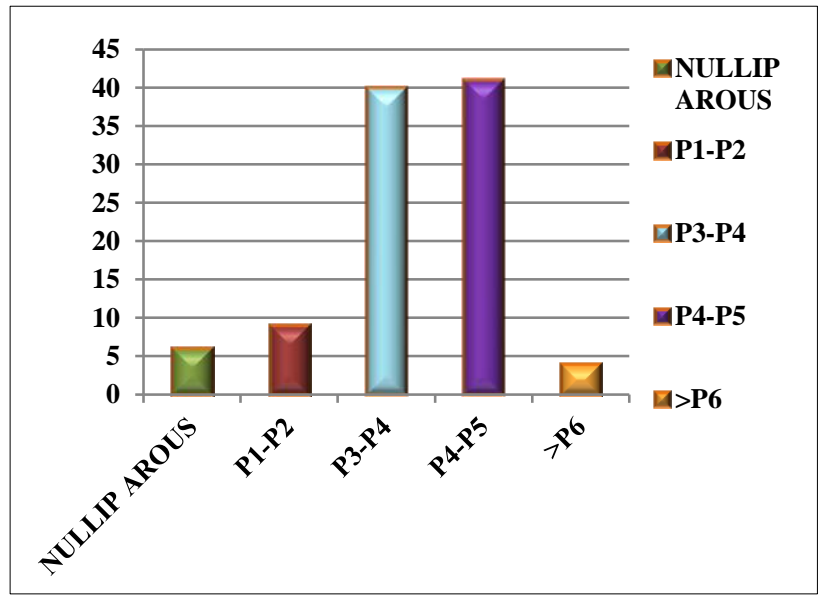

Figure 4: Parity.

\section{HPE of endometrium}

Figure 5 shows histopathological changes of endometrium in the $\mathrm{D}$ and $\mathrm{C}$ procedure done preoperatively which is sent to for pathological evaluation. 37 cases showed features of atrophic endometrium, 14 cases had proliferative endometrium, 14 
cases had endometrial hyperplasia which might be both simple or atypical. ${ }^{8}$ Cases had endometrial polyp. 1 case had features of serous carcinoma, while none of them has sarcomatous changes. In about 18 cases curettage was not done either due to cervical stenosis or no endometrial sample was obtained.



Figure 5: Histopathological changes of endometrium.

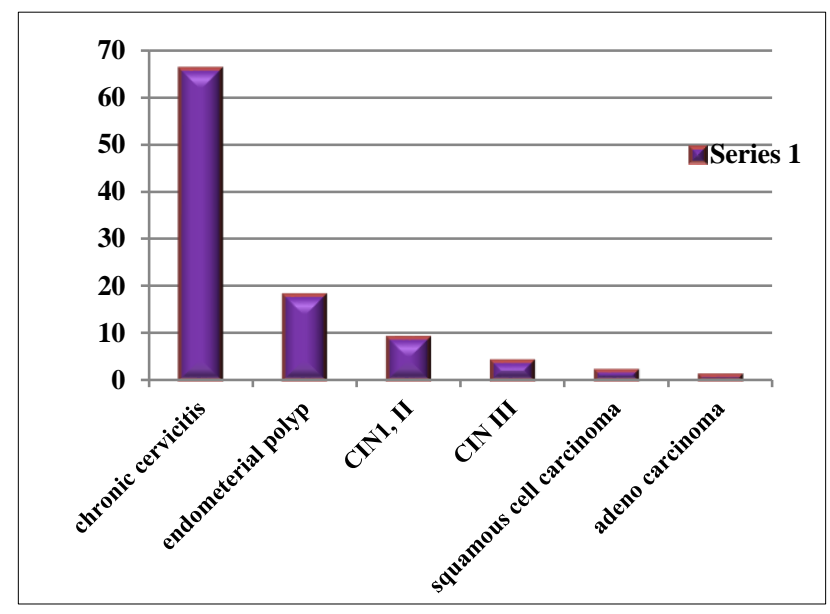

Figure 6: Histopathological findings of cervix.

\section{HPE of endocervix}

Figure 6 shows histopathological features of cervix in the D\&C procedure done preoperatively and sent for histopathological evaluation. Majority i.e., 69 cases showed features of chronic cervicitis, 12 cases showed dysplasia, 2 cases showed features of squamous cell carcinoma, while only 1 case had adeno carcinomatous changes in the cervix.

\section{Pap smear}

Figure 7 shows Pap Smear changes of these 100 patients proved to have adenomyosis. 56 cases had inflammatory changes, 13 cases had dysplastic changes, 12 cases had malignant features.

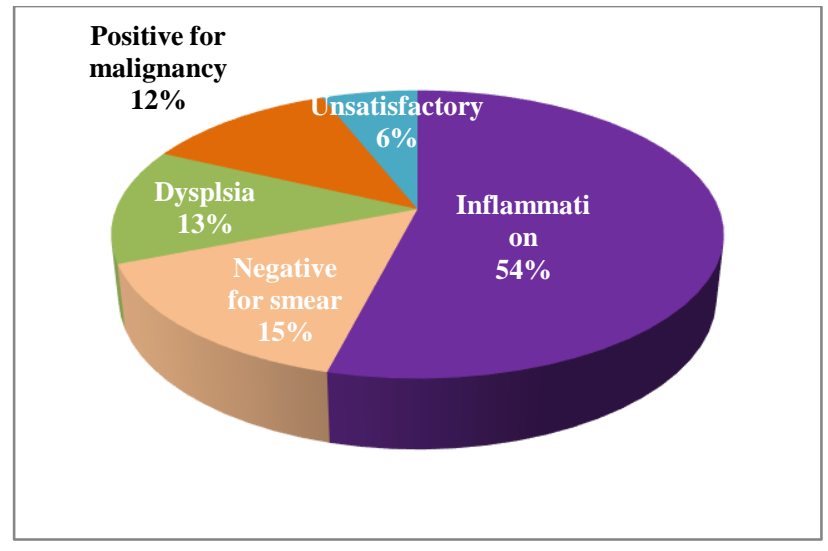

Figure 7: Pap Smear.

\section{DISCUSSION}

Adenomyosis is an important clinical challenge in gynecology and healthcare economics; in its fully developed form, hysterectomy is often used to treat it in premenopausal and perimenopausal women. Symptoms of adenomyosis typically include menorrhagia, pelvic pain and dysmenorrhea. Moreover, adenomyosis and leiomyomas commonly coexist in the same uterus, and differentiating the symptoms for each pathological process can be problematic. Although it has been recognized for over a century, reliable epidemiological studies on this condition are limited, because only postoperative diagnoses were possible. Because of the widespread use of hysterectomy as the primary therapeutic option, adenomyosis has never been fully characterized.

The first description of the condition initially referred to as adenomyoma was provided in 1860 by the German pathologist Carl von Rokitansky, who found endometrial glands in the myometrium and subsequently referred to this finding as cyst sarcoma adenoids uterinum. ${ }^{5,6}$ The modern definition of adenomyosis was provided in 1972 by Bird who stated: Adenomyosis may be defined as the benign invasion of endometrium into the myometrium, producing a diffusely enlarged uterus which microscopically exhibits ectopic non-neoplastic, endometrial glands and stroma surrounded by the hypertrophic and hyperplastic myometrium.

\section{CONCLUSION}

Adenomyosis was found to be the most common cause of abnormal uterine bleeding in women of perimenopausal age group. In the last decade, a significant improvement has been achieved in understanding and management of adenomyosis. Adenomyosis has become a clinical entity rather than just a histological diagnosis.

Hence the histopathological analysis of endometrium and cervix is analysed and its association with other risk factors is done in this study. 


\section{ACKNOWLEDGMENTS}

Authors would like to thank all those who are cooperative and the scholars whose articles helped us for comparison and all the references. Superintendent, Government Victoria hospital, Dr. D. Hemalatha Devi. Professor Dr. YLN Rao (MD), pathology professor Dr. Bhagya Lakshmi, Colleagues, house surgeons who are helpful for this study.

Funding: No funding sources Conflict of interest: None declared

Ethical approval: The study was approved by the Institutional Ethics Committee

\section{REFERENCES}

1. Konar H, Duttas DC. Textbook of gynecology, $7^{\text {th }}$ edition, Jaypee publishers pvt. limited, New Delhi, India, Chapter no. 22; 2016:257-259.

2. Padubidri VG, Daftary SN. Howkins and Borne SHAWS textbook of gynecology $16^{\text {th }}$ edition, Reed Elsevier India Private Limited, New Delhi, India, chapter no.30; 2015:418-423.
3. Berek JS. and Novaks. Gynecology $14^{\text {th }}$ edition, Lippincott Williams and Wilkins, New York, London, chapter no.29; 2014:1128-1131.

4. Bhosle A, Fonseca M. Evaluation and histopathological correlation of abnormal uterine bleeding in perimenopausal women. Bombay Hosp J. 2019;52:69-72.

5. Benagiano G, Brosens I. History of adenomyosis. Best Pract Res Clin Obstet Gynaecol. 2006;20:44963.

6. Renner SP, Lermann J, Hackl J, Burghaus S, Oppelt $\mathrm{P}$, Binder $\mathrm{H}$, et al. Chronische Erkrankung. Endometriose. Geburtshilfe and Frauenheilkunde. 2012;72(10):914-9.

Cite this article as: Matangi $\mathrm{A}$, Manukonda A, Bommiti A. Study of endometrial and cervical histopathology in adenomyosis. Int J Reprod Contracept Obstet Gynecol 2020;9:1779-83. 